\title{
Определение доминирующего механизма безызлучательного возбуждения ионов марганца в II-VI полумагнитных полупроводниках \\ Черненко А.В.
}

ИФТТ РАН, 142432, Черноголовка, ул. Академик Осипьяна, 2

DOI 10.34077/Semicond2019-345

Допирование марганцем полупроводников группы II-VI и низкоразмерных структур на их основе приводит к эффективному тушению электро- и фотолюминесценции при условии, что энергия электронного возбуждения кристалла превышает энергию внутрицентрового перехода иона $\mathrm{Mn}^{2+} \mathrm{E}_{\mathrm{Mn}} \approx 2.1$ эВ [1]. Внутрицентровой дипольный переход ${ }^{4} \mathrm{~T}_{1} \rightarrow{ }^{6} \mathrm{~A}_{1}$ в $\mathrm{Mn}^{2+}$ запрещен правилами отбора, но кристаллическое поле и спин-орбитальное взаимодействие делают эти переходы слаборазрешенными, что объясняет длинные времена жизни возбужденных состояний $\mathrm{Mn}^{2+}>1$ мксек. В этих условиях доминирующую роль может играть обменный механизм, хотя возможны переходы за счет мультипольных моментов электронной оболочки $\mathrm{Mn}^{2+}$ высших порядков. В отличие от диполь-дипольной передачи возбуждения, обменный механизм является спин-зависимым. Кроме прямого обменного механизма, возможен косвенный обменный механизм, связанный со специфической для полумагнитных полупроводников II-VI sp-d гибридизацией [2,3]. Несмотря на обилие экспериментальных данных, их противоречивость и зависимость от характеристик конкретных образцов не позволяет сделать однозначных выводов о доминирующем механизме передачи возбуждения ионам $\mathrm{Mn}^{2+}$ или о парциальных вкладах различных механизмов. В докладе предлагается несколько способов экспериментального выявления доминирующего механизма передачи возбуждения ионам $\mathrm{Mn}^{2+}$. Они основаны на характерных отличиях обменного и диполь-дипольного (диполь-мультипольного) механизмов: (i) спиновая зависимость первого и существование для него правил отбора (ii) дальнодействие первого механизма передачи возбуждения и короткодействие второго (iii) различная зависимость эффективности этих механизмов передачи энергии от размеров квантовых точек (нанокристаллов) (iv) возможность существенного усиления диполь-дипольного механизма передачи возбуждения посредством взаимодействия с поверхностными плазмонами

Спиновая зависимость обменного механизма приводит к существованию правил отбора по спину для спинов и суммы проекций спинов иона $\mathrm{Mn}^{2+}$ и экситонов (трионов). Проверка выполнения правил отбора является самым прямым доказательством доминирования обменного механизма. Кроме измерений в магнитном поле $[1,2,3]$, таковыми могли бы являться измерения оптически детектируемого магнитного резонанса в полумагнитных квантовых ямах и точках, поскольку микроволновое излучение позволяет селективно заселять расщепленные магнитным полем уровни ионов марганца и, таким способом, управлять темпом безызлучательной рекомбинации.

Ещё одним способом выявления доминирующего механизма явилось бы использование эффекта гигантского усиления безызлучательной передачи энергии посредством диполь-дипольного механизма ионам $\mathrm{Mn}^{2+}$ за счет взаимодействия квантовых ям или точек с поверхностными плазмонами металлических наночастиц, локализованных близ поверхности структур. В то же самое время плазмонное усиление поля никак не влияет на обменный механизм передачи возбуждения ионам $\mathrm{Mn}^{2+}$. Усиление безызлучательной передачи энергии такого типа интенсивно изучается в последнее время [4]. Магнитооптические измерениями структур как с плазмонным усилением, так и без него позволило бы оценить вклад диполь-дипольного механизма в передачу энергии ионам $\mathrm{Mn}^{2+}$.

В дополнение к двум способам, упомянутым выше, рассмотрены и другие предложения по выявлению доминирующего механизма, основанные на перечисленных выше специфических особенностях.

[1] Chernenko A. V. et al. Phys. Rev. B 72 045302(2005).

[2] A.V. Chernenko et al. J. Phys.: Condens. Matter 22, 355306(2010).

[3] А.В. Черненко ФТП, 49, 1629 (2015).

[4] Liang-Yan Hsu et al. J. PhysChemLett., 8, 2357(2017). 